\title{
Testicular germ cell tumor: Short and long-term side effects of treatment among survivors
}

\author{
THIERRY GIL ${ }^{1}$, SPYRIDON SIDERIS ${ }^{1}$, FOUAD AOUN ${ }^{2}$, ROLAND VAN VELTHOVEN $^{2}$, \\ NICOLAS SIRTAINE ${ }^{3}$, MARIANNE PAESMANS ${ }^{4}$, LIEVEKE AMEYE $^{4}$, AHMAD AWADA $^{1}$, \\ DANIEL DEVRIENDT ${ }^{1}$ and ALEXANDRE PELTIER ${ }^{2}$
}

Departments of ${ }^{1}$ Oncology, ${ }^{2}$ Urology and ${ }^{3}$ Pathology; ${ }^{4}$ Department of Biostatistics, Data Center, Jules Bordet Institute, University ULB of Brussels, B-1000 Brussels, Belgium

Received April 9, 2015; Accepted December 11, 2015

DOI: $10.3892 / \mathrm{mco} .2016 .960$

\begin{abstract}
Long-term prognosis of germ cell tumor (GCT) types is excellent, however, treatment is associated with non-negligible complication rates and a negative impact on quality of life. The present study described treatment results in terms of survival, both short and long-term toxicity, and paternity rates in a cohort of patients treated at Jules Bordet Institute, University ULB of Brussels (Brussels, Belgium). The present study analyzed the data of a cohort of patients with GCT types. Pre-operative patient and tumor characteristics were described. Performance status, pulmonary function tests and renal clearance prior to chemotherapy were noted. Chemotherapeutic regimens and their associated toxicities were analyzed. The duration to event-free, cancer-specific and overall survivals were estimated using Kaplan-Meier curves. A total of 115 patients (median age, 31-years-old) were treated for a GCT at Jules Bordet Institute. At a median follow-up of 6-years, $11(10 \%)$ patients had relapsed and $2(2 \%)$ developed a second malignant neoplasm. At the final follow-up, $97(89 \%)$ and $6(5.5 \%)$ patients exhibited complete and partial remission, respectively. A total of $6 \%$ of patients exhibited a progressive disease. In terms of short-term toxicity, $11 \%$ of patients presented with febrile neutropenia. The 10-year overall survival rate and relapse-free survival rate were 93.4 and $89.8 \%$, respectively. The paternity rate post-treatment was $27 \%$. Testicular GCT survivors suffered from short- and long-term treatment-associated side effects on both a physical and psychological level. A long-term close follow-up is necessary in order to assist the patient with these treatment-induced complications.
\end{abstract}

Correspondence to: Dr Fouad Aoun, Department of Urology, Jules Bordet Institute, University ULB of Brussels, 1 Rue Héger-Bordet, B-1000 Brussels, Belgium

E-mail: fouad.aoun@bordet.be

Key words: quality of life, paternity, testicular cancer, testicular cancer survivors, adverse effects

\section{Introduction}

Testicular germ cell tumors (TGCT) represent the most common solid tumor type affecting young men aged between 18 and 35-years-old (1). The incidence and mortality are known to vary across countries (2). Despite the increase in its incidence during the last decade, particularly in Western countries, the number of patients dying from the disease is stable due to increased cure rates (3). Improved survival stems predominantly from increased staging accuracy, adequate early treatment based on a multidisciplinary approach, the use of platinum-based regimens, careful follow-up and salvage therapies. In the oncologic center of excellence, cure rates as high as $90 \%$ at 10 years were achieved (4). These good results draw attention to the quality of life of survivors. In addition, the importance of this issue becomes more apparent when considering that the vast majority of these survivors are $<40$-years-old (1).

Notably, to achieve these high rates of cure, even in high risk patients, several treatment strategies and regimens are often delivered. These modalities are associated with a significant quantity of complications and a negative impact on quality of life (5). Sperm abnormalities are frequently observed in patients with TGCT (6). Furthermore, orchiectomy, chemotherapy and radiation therapy can also impair fertility (7). The risk for solid secondary tumor types increases with a younger age at radiotherapy or chemotherapy, and remains significantly elevated for at least 35 years (8). The risk of leukemia is also associated with the dose of chemotherapy, with a cumulative dose-disease association regarding cisplatin and acute myeloid leukemia (9). Pulmonary toxicity and infections are common problems in the long-term setting (10). Hypogonadism and metabolic syndrome are prevalent among testicular cancer survivors (11). Therefore, subsequent cardiovascular events are higher compared with the general population (12). Psychological disturbances, emotional liabilities, physical and/or cognitive tiredness, and depression are common long-term complaints (13). Long-term close follow-up due to the possibility of recurrence expose such patients to anxiety and uncertainty (13). Understandably, all these events adversely affect the quality of life, which is deteriorated in $>1 / 3$ of patients (14). 
The present study analyzed the data of a cohort of patients with TGCT treated at the Jules Bordet Institute. The aim of the present study was to report the experiences of TGCT management over the last 10 years, particularly in terms of survival for each prognostic group of TGCT. The long-term follow-up, the impact of treatment on patient metabolic parameters and the impact of the treatment on the quality of life were investigated.

\section{Materials and methods}

The present study involved a cohort of 115 consecutive patients with GCT, treated and followed-up at the Jules Bordet Institute, University ULB of Brussels (Brussels, Belgium) between September 2000 and December 2010. The collected data were pooled and retrospectively analyzed. The project was approved by the Institute Jules Bordet Ethics Review Committee in August 2013. All patients with testicular germ cell neoplastic disease, having received their initial treatment and under periodic follow-up care at the Jules Bordet Institute, were included. Patients with histology other than germ cell neoplastic disease were excluded.

Socio-demographic characteristics, physical examination and tumor markers, including human chorionic gonadotropin (HCG), $\alpha$ fetoprotein (AFP) and lactate dehydrogenase (LDH), were obtained for all patients. A complete blood test analysis was also performed at diagnosis. Local disease was assessed by a testicular echography, whereas retroperitoneal extension and distant metastases were assessed using a thoracoabdominal computed tomography scan. A bone scan was requested in symptomatic patients or in men with elevated alkaline phosphatase. A magnetic resonance imaging scan of the brain was reserved for poor risk metastatic patients or patients with neurological symptoms. The modalities of treatment administered to patients followed the principles of the European Society of Medical Oncology (ESMO) guidelines $(15,16)$. For stage I seminoma, surveillance was the preferred strategy. In the presence of certain risk factors, including rete testis infiltration or tumor size $>4 \mathrm{~cm}$, one course of carboplatin was applied or radiotherapy (20 Gy in 10 fractions to para aortic target volume). In stage IIA seminoma, with the presence of lymph nodes sized 1-2 cm, both cisplatin-based chemotherapy and radiation therapy to para aortic and ipsilateral iliac lymph nodes are valid options. In stage II B/C seminoma, three cycles of bleomycin, etoposide and cisplatin (BEP) was the standard of care. In the case of contra-indication to the use of bleomycin, four cycles of etoposide-cisplatin (EP) were alternatively used. In stage III seminoma, three cycles of bleomycin, etoposide and cisplatin (BEP) was the standard of care for patients with good prognosis, according to the International Germ Cell Cancer Collaborative Group (IGCCCG), and four cycles of BEP for those with an intermediate prognosis. In the case of residual tumor post-chemotherapy, a 2-fluor-2-deoxy-D-glucose positron emission tomography (PET) scan was performed if the lesion was $>3 \mathrm{~cm}$. In the case of a positive PET, surgical resection of the residual lesion was performed. Patients with non-seminoma (NS)GCT stage I were divided into two categories based on the presence or absence of vascular invasion. In the absence of lymphovascular invasion, surveillance was preferred, whereas high risk patients received two cycles of BEP. Primary chemotherapy for stage II and III
NSGCT consisted of three or four courses of BEP, depending on the IGCCCG risk classification. Patients with good prognosis received three cycles of BEP, or four cycles of EP if bleomycin was contra-indicated. Patients with intermediate risk were treated with four cycles of BEP or four cycles of etoposide, ifosfamide and cisplatin (VIP) if bleomycin raised concerns for lung toxicity. Prophylactic administration of growth factors, including granulocyte colony stimulating factor (GCSF), was recommended only in cases of infectious complications following the first courses of chemotherapy. In the case of relapse, the regimen most frequently used was VIP, followed by paclitaxel, ifosfamide and cisplatin (TIP). High-dose chemotherapy in association with autologous stem cell transplantation was used in selected patients.

The post-treatment follow-up respected the principles of the ESMO guidelines. Statistical analysis was performed using the SAS System version 9.4 (SAS Institute Inc., Cary, NC, USA). Descriptive summary statistics were used to describe the patient's population and the administered treatments. Treatment-associated toxicities were reported using proportions. Survival analysis was performed using non-parametric analysis (Kaplan-Meier estimates) and the log-rank test was used to compare Kaplan-Meier curves. $\mathrm{P}<0.05$ was considered to indicate a statistically significant difference.

\section{Results}

Baseline and tumor characteristics of the study population were summarized in Tables I and II. Overall, a total of 115 patients (median age, 31-years-old) were enrolled in the present study, with a median follow-up of 6 years. Cryptorchidism was the most common risk factor for TGCTs identified in $8 \%$ of the enrolled patients. Of the patients, 4 had co-morbidities. Positive family history for GCT was observed in $1 \%$ of patients and $10 \%$ of patients had a family history of another cancer type. At the moment of diagnosis, 44 (38\%) patients were single and only 19 (17\%) had children. The life habits of the patients were also documented at diagnosis. More than half of the patients failed to answer the question concerning the use of marijuana, and of the 56 patients who did answer, 6 (5\%) admitted to be a regular user. With regards to the localization of the primary tumor, the testis was the most common place with an equal distribution among the two testes. With the exception of 5 patients, the remaining patients were initially treated with surgery. The pathology of the specimen was described in Table I. In stage I, 11 patients were followed-up without treatment, whereas 35 and 11 patients received adjuvant chemotherapy and radiation therapy, respectively. The patients (47.5\%) were classified as stage II and III and received chemotherapy based on the ESMO guidelines. In terms of prognosis, $70 \%$ of patients were classified with a good, $13 \%$ as intermediate and $17 \%$ as poor diagnosis, according to the IGCCCG classification (17). Pulmonary function tests, renal clearance of creatinine and Eastern Cooperative Oncology Group performance status at the initiation of chemotherapy, as well as the extent of the disease were summarized in Table III. The modalities of the first regimen and treatment-associated toxicities were summarized in Table IV. The incidence of febrile neutropenia was $11 \%$. No allergic reaction was observed and in only $3 \%$ of patients, bleomycin was either avoided or discontinued due to lung toxicity. A 
Table I. Patient characteristics.

A, Risk factors

\begin{tabular}{|c|c|c|}
\hline Characteristic & $\begin{array}{l}\text { No. patients } \\
\quad(n=115)\end{array}$ & $\%$ \\
\hline \multicolumn{3}{|l|}{ Cryptorchidism } \\
\hline No & 88 & 76 \\
\hline Yes & 9 & 8 \\
\hline Unknown & 18 & 16 \\
\hline \multicolumn{3}{|l|}{ Orchidopexy } \\
\hline No & 92 & 80 \\
\hline Yes & 8 & 7 \\
\hline Unknown & 15 & 13 \\
\hline \multicolumn{3}{|l|}{ Trauma } \\
\hline No & 95 & 83 \\
\hline Yes & 4 & 3 \\
\hline Unknown & 16 & 14 \\
\hline \multicolumn{3}{|l|}{ Atrophy } \\
\hline No & 95 & 83 \\
\hline Yes & 5 & 4 \\
\hline Unknown & 15 & 13 \\
\hline \multicolumn{3}{|c|}{ Gonadal dysgenesis } \\
\hline No & 99 & 86 \\
\hline Yes & 1 & 1 \\
\hline Unknown & 15 & 13 \\
\hline \multicolumn{3}{|l|}{ Hypogonadism } \\
\hline No & 97 & 84 \\
\hline Yes & 3 & 3 \\
\hline Unknown & 15 & 13 \\
\hline \multicolumn{3}{|c|}{ Genetic syndrome } \\
\hline No & 99 & 86 \\
\hline Yes & 0 & 0 \\
\hline Unknown & 16 & 14 \\
\hline
\end{tabular}

B, Past medical history

\begin{tabular}{lcc}
\hline Characteristic & $\begin{array}{c}\text { No. patients } \\
(\mathrm{n}=115)\end{array}$ \\
\hline
\end{tabular}

Liver dysfunction

No

Yes

Unknown

17

1

Sub fertility

No

16

Yes

Unknown

97

Sterility

No

Yes

Unknown

Other

97

Yes

Unknown/no
Table I. Continued.

C, Further socio-demographic characteristics

\begin{tabular}{lcr}
\hline Characteristic & $\begin{array}{c}\text { No. patients } \\
(\mathrm{n}=115)\end{array}$ & $\%$ \\
\hline Family history of & & \\
germ cell cancer & & \\
No & 94 & 1 \\
Yes & 1 & 17 \\
Unknown & 20 &
\end{tabular}

Family history of another cancer type

$\begin{array}{lll}\text { No } & 81 & 70\end{array}$

Yes $12 \quad 10$

$\begin{array}{lll}\text { Unknown } & 22 & 20\end{array}$

Marital status

$\begin{array}{lll}\text { Married } & 23 & 20\end{array}$

Partner $\quad 9 \quad 8$

Single $\quad 44 \quad 38$

Unknown $39 \quad 34$

Children at diagnosis

$\begin{array}{lll}\text { No } & 55 & 48\end{array}$

$\begin{array}{lll}\text { Yes } & 19 & 17\end{array}$

Unknown $\quad 41 \quad 35$

Allergy

$\begin{array}{lll}\text { No } & 75 & 65\end{array}$

$\begin{array}{lll}\text { Yes } & 9 & 8\end{array}$

$\begin{array}{lll}\text { Unknown } & 31 & 27\end{array}$

$\mathrm{D}$, Life habits

\begin{tabular}{lcr}
\hline Characteristic & $\begin{array}{c}\text { No. patients } \\
(\mathrm{n}=115)\end{array}$ & $\%$ \\
\hline Sport & & \\
No & 31 & 27 \\
Yes & 20 & 17 \\
Unknown & 64 & 56 \\
Tobacco & & \\
No & 37 & 32 \\
Yes & 46 & 40 \\
Unknown & 32 & 28 \\
Alcohol & & 57 \\
No & 66 & 15 \\
Yes & 17 & 28 \\
Unknown & 32 & \\
Drugs & & 50 \\
No & 57 & 1 \\
Yes & 2 & 49 \\
Unknown & 56 & 44 \\
Marijuana & & 51 \\
No & 59 & \\
Yes & 50 & \\
Unknown & & \\
\hline
\end{tabular}


Table II. Tumor characteristics.

\begin{tabular}{|c|c|c|}
\hline Characteristic & $\begin{array}{l}\text { No. patients } \\
\quad(n=115)\end{array}$ & $\%$ \\
\hline \multicolumn{3}{|l|}{ Primary localization } \\
\hline Testis & 101 & 88 \\
\hline Mediastinum & 1 & 1 \\
\hline Retroperitoneum & 13 & 11 \\
\hline \multicolumn{3}{|l|}{ Initial histology } \\
\hline Seminoma & 67 & 58 \\
\hline Embryonal carcinoma & 19 & 17 \\
\hline Choriocarcinoma & 2 & 2 \\
\hline Teratoma & 2 & 2 \\
\hline Yolk sac tumor & 1 & 1 \\
\hline Mixed & 17 & 15 \\
\hline Other & 7 & 6 \\
\hline \multicolumn{3}{|l|}{ Prognostic group ICCCG } \\
\hline Good & 81 & 70 \\
\hline Intermediate & 15 & 13 \\
\hline Poor & 19 & 17 \\
\hline \multicolumn{3}{|l|}{ Curative treatment } \\
\hline Surgery, RT, chemo & 4 & 3 \\
\hline Sugery, RT, no chemo & 31 & 27 \\
\hline Surgery, no RT, chemo & 66 & 57 \\
\hline Sugery, no RT, no chemo & 9 & 8 \\
\hline No surgery, RT, chemo & 3 & 3 \\
\hline No surgery, no RT, chemo & 2 & 2 \\
\hline \multicolumn{3}{|l|}{ Initial tumor markers } \\
\hline \multicolumn{3}{|l|}{$\operatorname{AFP}(n g / m l)$} \\
\hline No. patients used & 68 & - \\
\hline Mean \pm standard deviation & $247 \pm 778$ & - \\
\hline Median (min-max) & $3.8(0.1$ to 4956$)$ & - \\
\hline \multicolumn{3}{|l|}{$\mathrm{hCG}(\mathrm{mU} / \mathrm{ml})$} \\
\hline No. patients used & 61 & - \\
\hline Mean \pm standard deviation & $465 \pm 1411$ & - \\
\hline Median (min-max) & $1.3(0.1$ to 6705$)$ & - \\
\hline \multicolumn{3}{|l|}{ LDH (UI/l) } \\
\hline No. patients used & 55 & - \\
\hline Mean \pm standard deviation & $771 \pm 1283$ & - \\
\hline Median (min-max) & $480(8-9390)$ & - \\
\hline \multicolumn{3}{|l|}{$\mathrm{CEA}(\mu \mathrm{g} / \mathrm{l})$} \\
\hline No. patients used & 33 & - \\
\hline Mean \pm standard deviation & $2.3 \pm 1.6$ & - \\
\hline Median (min-max) & $2.5(0.1-7.7)$ & - \\
\hline
\end{tabular}

ICCCG, International Germ Cell Cancer Collaborative Group; RT, radiotherapy; chemo, chemotherapy; AFP, alpha fetoprotein; hCG, human chorionic gonadotropin; LDH, lactate dehydrogenase; CEA, carcino-embryonic antigen.

total of $17 \%$ of patients reported interpersonal and professional concerns during treatment.

At the long-term follow-up, 8 patients had succumbed to mortality; 6 had succumbed to their disease and 2 to
Table III. ECOG performance status, extend of the disease, pulmonary function testing, dilution of carbon monoxide and cryopreservation of semen, in 81 patients at initiation of chemotherapy.

\begin{tabular}{|c|c|c|}
\hline Characteristic & No. patients & $\%$ \\
\hline \multicolumn{3}{|c|}{ ECOG performance status } \\
\hline 0 & 66 & 89 \\
\hline 1 & 7 & 10 \\
\hline 2 & 0 & 0 \\
\hline 3 & 1 & 1 \\
\hline \multicolumn{3}{|c|}{ Extend of the disease } \\
\hline Lymph node & 36 & 42 \\
\hline Lung & 9 & 11 \\
\hline Liver & 2 & 2 \\
\hline Bone & 1 & 1 \\
\hline CNS & 6 & 7 \\
\hline No meta & 31 & 36 \\
\hline Unknown & 1 & 1 \\
\hline \multicolumn{3}{|c|}{ Measurable lesions } \\
\hline No & 9 & 17 \\
\hline Yes & 43 & 83 \\
\hline \multicolumn{3}{|l|}{ Stage } \\
\hline IA & 33 & 45 \\
\hline IB & 4 & 5 \\
\hline IIA & 2 & 3 \\
\hline IIB & 3 & 4 \\
\hline IIC & 1 & 1 \\
\hline IIIA & 8 & 11 \\
\hline IIIB & 9 & 12 \\
\hline IIIC & 14 & 19 \\
\hline \multicolumn{3}{|l|}{ RFE } \\
\hline Normal & 56 & 69 \\
\hline Abnormal & 4 & 5 \\
\hline Missing info & 21 & 26 \\
\hline \multicolumn{3}{|c|}{ Cryopreservation } \\
\hline No & 7 & 9 \\
\hline Yes & 49 & 61 \\
\hline Unknown & 25 & 30 \\
\hline \multicolumn{3}{|c|}{ Renal clearance EDTA } \\
\hline Normal & 57 & 70 \\
\hline Abnormal & 2 & 3 \\
\hline Missing info & 22 & 27 \\
\hline
\end{tabular}

unrelated causes. Relapses were observed in 11 patients and 2 patients developed a second primary malignancy. The regimen most frequently used for relapses was VIP. Among survivors, complete and partial remission of the disease was achieved in 89 and $5 \%$ of patients, respectively. The 5-year overall survival rate was $93 \%$ (Fig. 1). The event free survival rate at 5 years was $90 \%$ (Fig. 2). The poor prognosis group 
Table IV. Modalities of first line chemotherapy.

\begin{tabular}{|c|c|c|}
\hline Characteristic & No. patients & $\%$ \\
\hline \multicolumn{3}{|l|}{ Type of chemotherapy } \\
\hline BEP & 37 & 51 \\
\hline $\mathrm{EP}$ & 2 & 3 \\
\hline VIP & 3 & 4 \\
\hline TIP & - & - \\
\hline Carboplatin & 24 & 33 \\
\hline Other & 6 & 9 \\
\hline \multicolumn{3}{|l|}{ High dose chemotherapy } \\
\hline No & 70 & 97 \\
\hline Yes & 2 & 3 \\
\hline \multicolumn{3}{|l|}{ Stem cell transfusion } \\
\hline No & 70 & 97 \\
\hline Yes & 2 & 3 \\
\hline \multicolumn{3}{|l|}{ Number of cycles administered } \\
\hline No. patients used & 70 & \\
\hline Mean \pm standard deviation & $2.6 \pm 1.3$ & \\
\hline Median (min-max) & $3(1-6)$ & \\
\hline \multicolumn{3}{|l|}{ Platine cumulative dose } \\
\hline No. patients used & 41 & \\
\hline Mean \pm standard deviation & $317 \pm 83$ & \\
\hline Median (min-max) & $300(100-500)$ & \\
\hline \multicolumn{3}{|l|}{ Bleomycin cumulative dose } \\
\hline No. patients used & 37 & \\
\hline Mean \pm standard deviation & $256 \pm 80$ & \\
\hline Median (min-max) & $270(90-450)$ & \\
\hline \multicolumn{3}{|l|}{ Concomitant medications } \\
\hline No & 10 & 16 \\
\hline Primary & 52 & 81 \\
\hline Secondary & 2 & 3 \\
\hline
\end{tabular}

BEP, Bleomycin-Etoposide-Cisplatin; EP, Etoposide-Cisplatin; VIP, Etoposide-Ifosfamide-Cisplatin; TIP,Paclitaxel-Ifosfamide-Cisplatin

had a statistically significant shorter duration to relapse compared with the groups of good or intermediate prognosis ( $\mathrm{P}=0.002$; Fig. 3).

Of the patients, 1/3 managed to have children following treatment. The most often used modality was in vitro fertilization. During the follow-up period, $8 \%$ of patients divorced and $8 \%$ changed profession. Cannabis withdrawal was noted in 2 patients and $60 \%$ began or continued physical activity. Weight, blood pressure and pulse were not statistically different between the first year post-treatment and the final follow-up. Of these patients, $1 / 5$ st a new medication to control treatment-associated side effects, including hypercholesterolemia, hypogonadism and depression.

\section{Discussion}

The present study highlighted the good oncological outcomes of patients suffering with testicular germ cell cancer.

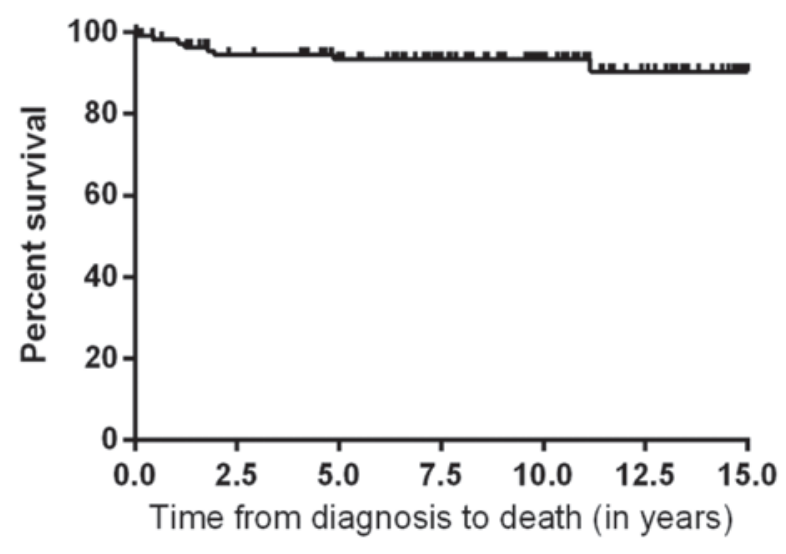

Figure 1. Kaplan-Meier curve for overall survival. The 5 year overall survival rate was $93 \%(n=115)$. Notably, 8 patients succumbed to mortality.

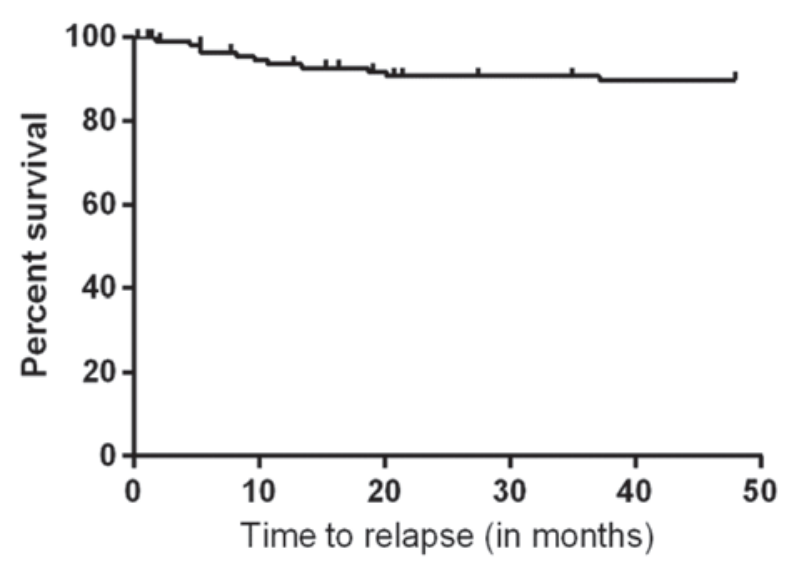

Figure 2. Kaplan-Meier curve of event free survival. Event free survival rate at 5 years was $90 \%$, with 11 relapses.

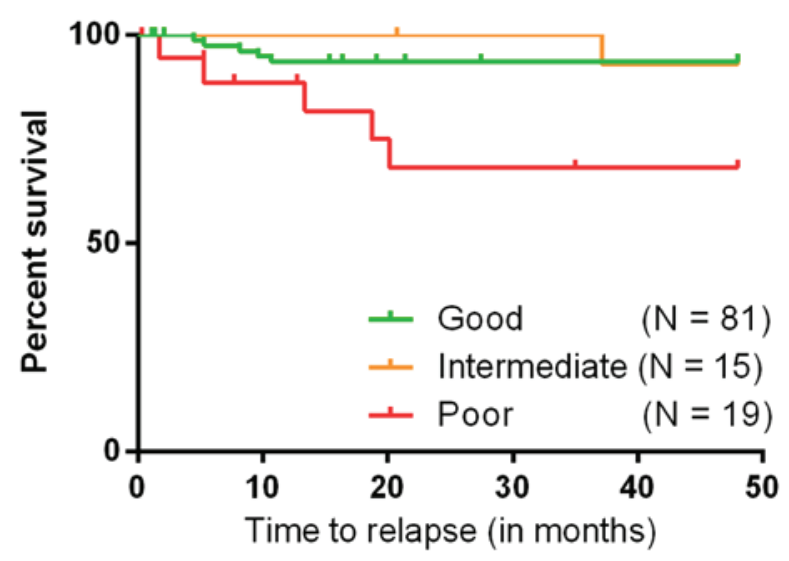

Figure 3. Kaplan-Meier curve for time to relapse for the good, intermediate and poor prognosis groups of patients with testicular germ cell tumors.

Furthermore, high compliance rates were observed for starting and maintaining physical activity, as well as avoiding weight gain. However, cannabis withdrawal was less likely among survivors as only $2 / 6$ regular users stopped consumption. Only $1 / 5$ of patients started a new medication to control blood pressure, dyslipidemia, hypogonadism or depression. 
The latter symptom was less frequent in patients living in couples. Of note, only $1 / 4$ patients had fathered children prior to the diagnosis and 1/3 managed to father children following the treatment. The vast majority of patients were healthy males with no co-morbidities, and cryptorchidism was the most common risk factor identified in the cohort of patients. Notably, only $1 \%$ of patients had a positive family history of TGCT. These findings are in accordance with a previous meta-analysis indicating that cryptorchidism and familial history of testicular cancer augmented the risk of TGCT to 4.8 and 3 , respectively (18). An estimated $1.4 \%$ of men with newly diagnosed TGCT reported a positive family history for this cancer (18). A pooled segregation analysis supported the existence of a Mendelian inheritance in multiple-case TGCT families, with the evidence markedly favoring an autosomal recessive mechanism. Candidate gene analyses have had mixed results. Germline mutations in three Xq27 genes, KIT or DND1, as well as germline variants in the PDE11A have been associated with the risk of familial TGCT. More recent analyses have implicated KITLG, SPRY4, and BAK1 as sporadic testicular cancer susceptibility loci (19). Currently, medical literature does not support an association between alcohol consumption and testicular cancer, however, one previous study offered evidence of an association between smoking and moderate risk of TGCT $(20,21)$. Based on a previous epidemiological analysis, marital status was an independent predictor factor of improved overall survival and cancer-specific survival (22).

Chemotherapy regimens were well-tolerated and only $11 \%$ of patients developed febrile neutropenia. The use of GCSF concomitantly to the chemotherapy for testicular cancer is debatable. Bokemeyer et al (23) demonstrated that the concomitant use of GCSF with chemotherapy ameliorated chemotherapy-induced myelosuppression, allowed increased dose intensity of the treatment and generated more peripheral blood stem cells (23). In their study, the risk of neutropenic infections was $<20 \%$ for the group of good risk patients with metastatic disease, and prophylactic use of GCSF was not routinely recommended. For intermediate and poor risk patients where aggressive cis-platinum based regimens were used, the risk of febrile neutropenia was between 20 and 70\%, and prophylactic use of GCSF was beneficial. At present, the concomitant use of GCSF with high dose chemotherapy is advisable. In the present study, no statistically significant benefit in terms of overall survival was noted between patients taking GCSF with chemotherapy compared with patients without GCSF. However, more prospective studies are required in order to define the exact role of GCSF in the treatment of TGCTs.

In terms of survival, the present results are in the line with those of contemporary series (24). A multi-institutional European study performed in 27 countries revealed the 10 -year overall survival rates of $96 \%$ for testicular cancer (4). In the USA, the 5-year overall survival is $99 \%$ for localized disease, $96 \%$ for regional disease and $74 \%$ for advanced disease, based on the data of the National Cancer Institute's Surveillance, Epidemiology and Results (25). Prognostic factors associated with improved survival rates commonly found in the literature are: Younger age, marital status and early stage, all reach $\sim 100 \%$ of 1 year overall survival for stage I disease (26). In general, the constant improvement of overall cure rates is attributed substantially to early diagnosis and the use of cis-platinum-based chemotherapy regimens.

In terms of quality of life, several previous studies suggested that treatment of TGCT has a great impact on the overall status of the patients. From the physical point of view, the cardiovascular system is most commonly affected. A study by Huddart et al (12) showed that cardiovascular-associated co-morbidities are increased by $100 \%$ following treatment for testicular cancer (12). Bokemeyer et al (23) reported that in addition to Raynaud's phenomenon, high blood pressure, higher serum cholesterol, ototoxicity and peripheral neuropathy occurred (23). These late complications may affect the quality of life of TGCT survivors and were observed also in the present population. Previous studies revealed anxiety to be present in a great number of TGCT survivors causing fatigue, and decreased physical and mental ability (27). Social functioning was also impaired, suggesting the impact of the treatment on their ability to integrate and interact with others. Interpersonal problems and divorce were signaled in $17 \%$ of the current patients (28).

Fertility studies in men treated for testicular cancer have predominantly focused on follicle stimulating hormone levels and sperm quality parameters (29). Chemotherapy has the greatest impact on fertility, followed by radiotherapy and retroperitoneal lymph node dissection $(30,31)$. Fosså et al (28) reported that the paternity rate in 1,814 testicular cancer survivors was $71 \%$ and the duration from diagnosis until the birth of the first child after diagnosis was 6.6 years (28). The low paternity rate found in the present study is probably a hazardous finding associated with the small number of patients and missing information on paternity for many of them.

TGCT survivors have a risk of developing second malignancies $\sim 65-90 \%$ higher compared with age-matched controls. The relative risk for leukemia, associated with the previous use of etoposide, ranges between 3.5 and 4.5 and appears usually within ten years following the completion of treatment (32). In the present study, the incidence of a second primary solid cancer and treatment-associated acute leukemia is in accordance with the incidence reported in the literature.

In conclusion, the present findings are consistent with the results of most European and international studies in terms of epidemiological features and survival for patients with TGCT. Long-term surveillance and psychological support of patients with TGCT are mandatory. Lifestyle modifications are mandatory in order to avoid metabolic syndrome and cardiovascular morbidity. The usage of chemotherapy and radiation therapy in the adjuvant setting must be restricted to only the high risk patients. Prospective studies focusing on the quality of life of survivors are required in order to improve the management of testicular germ cell cancer survivors.

\section{References}

1. Sui W, Morrow DC, Bermejo CE and Hellenthal NJ: Trends in testicular cancer survival: A large population-based analysis. Urology 85: 1394-1398, 2015.

2. Bray F, Richiardi L, Ekbom A, Pukkala E, Cuninkova M and Møller H: Trends in testicular cancer incidence and mortality in 22 European countries: Continuing increases in incidence and declines in mortality. Int J Cancer 118: 3099-3111, 2006.

3. La Vecchia C, Bosetti C, Lucchini F, Bertuccio P, Negri E, Boyle P and Levi F: Cancer mortality in Europe, 2000-2004 and an overview of trends since 1995. Ann Oncol 21: 1323-1360, 2010. 
4. Trama A, Mallone S, Nicolai N, Necchi A, Schaapveld M, Gietema J, Znaor A, Ardanaz E and Berrino F; RARECARE Working Group: Burden of testicular, paratesticular and extragonadal germ cell tumours in Europe. Eur J Cancer 48: 159-169, 2012

5. Sender L and Zabokrtsky KB: Adolescent and young adult patients with cancer: A milieu of unique features. Nat Rev Clin Oncol 12: 465-480, 2015.

6. Petersen PM, Skakkebaek NE and Giwercman A: Gonadal function in men with testicular cancer: Biological and clinical aspects. APMIS 106: 24-34, 1998.

7. Tomlinson M, Meadows J, Kohut T, Haoula Z, Naeem A, Pooley K and Deb S: Review and follow-up of patients using a regional sperm cryopreservation service: Ensuring that resources are targeted to those patients most in need. Andrology 3: 709-716, 2015.

8. Ng AK, Kenney LB, Gilbert ES and Travis LB: Secondary malignancies across the age spectrum. Semin Radiat Oncol 20 $67-78,2010$.

9. Howard R, Gilbert E, Lynch CF, Hall P, Storm H, Holowaty E, Pukkala E, Langmark F, Kaijser M, Andersson M, et al: Risk of leukemia among survivors of testicular cancer: A population-based study of 42,722 patients. Ann Epidemiol 18 416-421, 2008

10. Travis LB, Beard C, Allan JM, Dahl AA, Feldman DR, Oldenburg J, Daugaard G, Kelly JL, Dolan ME, Hannigan R, et al: Testicular cancer survivorship: Research strategies and recommendations. J Natl Cancer Inst 102: 1114-1130, 2010.

11. Lackner JE, Märk I, Schatzl G, Marberger M and Kratzik C: Hypogonadism and androgen deficiency symptoms in testicular cancer survivors. Urology 69: 754-758, 2007.

12. Huddart RA, Norman A, Shahidi M, Horwich A, Coward D, Nicholls J and Dearnaley DP: Cardiovascular disease as a long-term complication of treatment for testicular cancer. J Clin Oncol 21: 1513-1523, 2003.

13. Malec JF, Romsaas EP, Messing EM, Cummings KC and Trump DL: Psychological and mood disturbance associated with the diagnosis and treatment of testis cancer and other malignancies. J Clin Psychol 46: 551-557, 1990.

14. Fleer J, Hoekstra HJ, Sleijfer DT and Hoekstra-Weebers JE: Quality of life of survivors of testicular germ cell cancer: A review of the literature. Support Care Cancer 12: 476-486, 2004

15. Huddart RA and Kataja VV; ESMO Guidelines Task Force: ESMO minimum clinical recommendations for diagnosis, treatment and follow-up of testicular seminoma. Ann Oncol 16 (Suppl 1): i40-i42, 2005.

16. Huddart RA and Purkalne G; ESMO Guidelines Task Force: ESMO minimum clinical recommendations for diagnosis, treatment and follow-up of mixed or non-seminomatous germ cell tumors (NSGCT). Ann Oncol 16 (Suppl 1): i37-i39, 2005.

17. International germ cell consensus classification: A prognostic factor based staging system for metastatic germ-cell cancers. International Germ Cell Cancer Collaborative Group. J Clin Oncol 15: 594-603, 1997.

18. Dieckmann KP and Pilchlmeier U: Clinical epidemiology of testicular germ cell tumors. World J Urol 22: 2-14, 2004.
19. Greene MH, Kratz CP, Mai PL, Mueller C, Peters JA, Bratslavsky G, Ling A, Choyke PM, Premkumar A, Bracci J, et al: Familial testicular germ cell tumors in adults: 2010 summary of genetic risk factors and clinical phenotype. Endocr Relat Cancer 17: R109-R121, 2010

20. Srivastava A and Kreiger N: Cigarette smoking and testicular cancer. Cancer Epidemiol Biomarkers Prev 13: 49-54, 2004.

21. Shinn EH, Swartz RJ, Thornton BB, Spiess PE, Pisters LL and Basen-Engquist KM: Testis cancer survivors' health behaviors: Comparison with age-matched relative and demographically matched population controls. J Clin Oncol 28: 2274-2279, 2010.

22. Abern MR, Dude AM and Coogan CL: Marital status independently predicts testis cancer survival-an analysis of the SEER database. Urol Oncol 30: 487-493, 2012.

23. Bokemever C, kuczyk MA, Köhne H, Einsele H, Kynast B and Schmoll HJ: Hematopoietic growth factors and treatment of testicular cancer: Biological interactions, routine use and dose-intensive chemotherapy. Ann Hematol 72: 1-9, 1996.

24. Damjanov I and Wewer-Albrechtsen N: Testicular germ cell tumors and related research from a historical point of view. Int J Dev Biol 57: 197-200, 2013.

25. Ferlay J, Shin HR, Bray F, Forman D, Mathers C and Parkin DM: GLOBOCAN 2008 v1.2, Cancer Incidence and Mortality Worldwide: IARC CancerBase No. 10 (Internet). International Agency for Research on Cancer, Lyon, France, 2010. http://globocan.iarc.fr. Accessed December 12, 2014.

26. Shanmugalingam T, Soultati A, Chowdhury S, Rudman S and Van Hemelrijck M: Global incidence and outcome of testicular cancer. Clin Epidemiol 5: 417-427, 2013.

27. Reilley MJ, Jacobs LA, Vaughn DJ and Palmer SC: Health behaviors among testicular cancer survivors. J Community Support Oncol 12: 121-128, 2014.

28. Fosså SD, Dahl AA and Loge JH: Fatigue, anxiety and depression in long-term survivors of testicular cancer. J Clin Oncol 21: 1249-1254, 2003

29. Hotaling JM, Patel DP, Vendryes C, Lopushnyan NA, Presson AP, Zhang C, Muller $\mathrm{CH}$ and Walsh TJ: Predictors of sperm recovery after cryopreservation in testicular cancer. Asian J Androl 18: 35-38, 2016

30. Magelssen H, Brydøy M and Fosså SD: The effects of cancer and cancer treatments on male reproductive function. Nat Clin Pract Urol 3: 312-322, 2006

31. Brydøy M, Fosså SD, Klepp O, Bremnes RM, Wist EA, Wentzel-Larsen T and Dahl O: Paternity following treatment for testicular cancer. Nat Cancer Inst 97: 1580-1588, 2005.

32. Richiardi L, Scélo G, Boffetta P, Hemminki K, Pukkala E, Olsen JH, Weiderpass E, Tracey E, Brewster DH, McBride ML, et al: Second malignancies among survivors of germ-cell testicular cancer: A pooled analysis between 13 cancer registries. Int J Cancer 120: 623-631, 2007. 